\title{
Identification of dentinogenic cell-specific surface antigens in odontoblast-like cells derived from adult dental pulp
}

\author{
Kyung-Jung Kang ${ }^{1}$, Chun-Jeih Ryu ${ }^{2}$ and Young-Joo Jang ${ }^{1 *}$ [D
}

\begin{abstract}
Background: Odontoblast is a unique progenitor that plays a role in dentin formation. So far, the dentinogenic differentiation of dental pulp stem cells and the role of surface molecules of odontoblasts in dentinogenesis are not well known yet. In this study, we obtained odontoblast-like cells from human dental pulp cells and screened odontoblast-specific cell surface antigens by decoy immunization.

Methods: Through decoy immunization with intact odontoblast-like cells derived from human dental pulp cells, we constructed 12 monoclonal antibodies (mAbs) of IgG type, and their binding affinities for cell surface of odontoblast-like cells were analyzed by flow cytometry. Immunoprecipitation, mass spectrometry, and immunohistochemistry were performed to demonstrate odontoblast-specific antigens. Odontoblasts were sorted by these mAbs using magnetic-activated cell sorting system, and their mineralization efficiency was increased after sorting.

Results: We constructed 12 mAbs of IgG type, which had a strong binding affinity for cell surface antigens of odontoblast-like cells. In human adult tooth, these mAbs accumulated in the odontoblastic layer between dentin and pulp and in the perivascular region adjacent to the blood vessels in the pulp core. Cell surface expression of the antigenic molecules was increased during odontogenic cytodifferentiation and decreased gradually as dentinogenic maturation progressed. Proteomic analysis showed that two representative antigenic molecules, OD40 and OD46, had the potential to be components for cell adhesion and extracellular matrix structures.

Conclusion: These results suggest that mAbs will be useful for detecting and separating odontoblasts from the primary pulp cells and other lineage cells and will provide information on the structures of extracellular matrix and microenvironment that appears during the dentinogenic differentiation.
\end{abstract}

Keywords: Adult stem cells, Dental pulp cells, Odontoblasts, Dentinogenic differentiation, Decoy immunization, Cell surface antigens

\section{Background}

The human dental pulp has a stem cell population with the ability to differentiate into various cell types, including neuronal cells, adipocytes, and odontoblasts [1, 2]. Much evidence has supported that postnatal dental pulp stem cells (DPSCs) isolated from the pulp tissue of human adult permanent tooth were useful in the repair of bone, cartilage, and the dental pulp itself [3]. Multiple

\footnotetext{
* Correspondence: yjjang@dankook.ac.kr

'Department of Nanobiomedical Science and BK21 PLUS Global Research Center for Regenerative Medicine, Dankook University, Cheonan 31116, South Korea

Full list of author information is available at the end of the article
}

signaling pathways, including Wnt, TGF $\beta / B M P$, and FGF signaling, are involved in regulating whole tooth development [4, 5]; however, the dentinogenic mechanism that determines the odontogenic fate in dental mesenchyme is a complex process and remains largely unknown. BMP2 induces dental pulp cell differentiation into odontoblast lineages [6-8]. BMP2 conditional knockout mice display the delayed odontoblast differentiation, abnormal dentin tubules, and decrease expression of tooth-related genes [9, 10], and BMP2 knockout dental papilla mesenchymal cells in murine are defective in odontoblastic differentiation and odontogenesis [11].

(c) The Author(s). 2019 Open Access This article is distributed under the terms of the Creative Commons Attribution 4.0 International License (http://creativecommons.org/licenses/by/4.0/), which permits unrestricted use, distribution, and 
Transcription of the dentin-specific genes is mediated by Dlx3/Osx signaling pathway in odontoblasts, which are downstream targets of BMP-2 signaling in osteogenic cells $[12,13]$. BMP4 is also essential for the progression of tooth development. Previous studies with knockout mice revealed that the arrest of tooth development caused by the deletion of Msx1 and Pax9 proteins is rescued by BMP4 overexpression [14, 15], and BMP4 signaling converges on Wnt activation during odontogenesis [16]. Both collagen and non-collagenous proteins are produced during odontogenic differentiation. Among non-collagenous proteins, dentin sialophosphoprotein (DSPP), osteocalcin, osteopontin, and dentin matrix protein-1 (DMP-1) are expressed. Both DMP-1 and DSPP play a role in early stages of odontogenesis and the mineralization of dentin [17]. Cells can be isolated using proper cell surface antigens to overcome the heterogeneity and lack of reproducibility that frequently appear during the use of adult stem cells and primarily differentiated progenitors. Previously, DPSCs have been isolated using STRO-1, CD105, or CD90 [1820]. Additionally, stem cell-specific surface markers from dental pulp have been searched for, and hDPSCs were purified using these markers [21, 22]. Dentin formation offers attractive perspectives for elaborate tooth regeneration and treatment, which enables the cure of tooth loss and restores the quality of life of the patients. Although isolation of odontoblasts from the pulp tissue must be achieved as a key element for efficient treatment, more specific cell surface markers for odontoblast identification are needed. In this report, we induced odontoblastic differentiation with human dental pulp cells (hDPCs) by BMP2/4 treatment and obtained odontoblast-like cells in the expanded culture. Through direct immunization with intact odontoblasts, we identified several candidate antibodies recognizing odontoblast-specific cell surface antigens.

\section{Methods}

\section{Cell culture and chemical treatment}

To primary culture of human dental pulp cells (hDPCs) and periodontal ligament cells (hDPLCs), third molar teeth were collected from dental surgery patients aged 19-29 years old under guidelines approved by the Dankook Dental Hospital, and the informed consent for all experiments using extracted teeth was obtained from all participants. Tissues were separated from the tooth and digested by $4 \mathrm{mg} / \mathrm{ml}$ dispase (Sigma-Aldrich) and $3 \mathrm{mg} /$ $\mathrm{ml}$ collagenase type I (Millipore) for $1 \mathrm{~h}$ at $37^{\circ} \mathrm{C}$. Single cell suspension isolated from pulp tissue was incubated with $\alpha$-MEM (Hyclone) containing 20\% fetal bovine serum (Hyclone), mycoplasma removal agent (Capricorn Scientific), and antibiotics (Lonza) at $37^{\circ} \mathrm{C}$ in $5 \% \mathrm{CO}_{2}$. For induction of cytodifferentiation, hDPCs were treated with $100 \mathrm{ng} / \mathrm{ml}$ FGF, $50 \mathrm{ng} / \mathrm{ml} \mathrm{TGF} \beta-1$ (Sino Biological), 10-100 ng/ml BMP2 (Sino Biological), and 10-100 ng/ ml BMP4 (Prospec). Human fetal osteoblast (hFOB) was cultured with DMEM/F-12 (Thermo) including 10\% FBS at $34{ }^{\circ} \mathrm{C}$ in $5 \% \mathrm{CO}_{2}$. For induction of osteoblastic differentiation, hFOB1.19 (ATCC, CRL-11372) cultured at 34 ${ }^{\circ} \mathrm{C}$ was transferred at $39^{\circ} \mathrm{C}$. For osteogenic induction of hPDLCs, cells were treated with $100 \mathrm{ng} / \mathrm{ml} \mathrm{BMP2}$ (Sino Biological) for 7 days. For mineral formation, cells were incubated in media containing the mineralization additives, which consist of $100 \mu \mathrm{M}$ ascorbic acid, $100 \mathrm{nM}$ dexamethasone, and $5 \mathrm{mM} \beta$-glycerophosphate.

\section{Construction of mAbs against cell surface molecules of odontoblast-like cells}

Production of mAbs against cell surface antigens was performed as previously reported with modification [22] and represented in Fig. 2A. Animal study protocol for antibody production was approved by the Institutional Animal Care and Use Committee of Dankook University. Briefly, cells were dissociated by using enzyme-free dissociation solution (Millipore), and $5 \times 10^{5}$ cells in $30 \mu \mathrm{l} \mathrm{PBS}$ ( $\mathrm{pH}$ 7.4) were injected into the hind footpads of 11 female BALB/c mice for immunization. To generate a panel of hybridomas producing antibodies that bound to the odontoblasts, odontoblasts and hDPCs were injected into the left and right hind footpads, respectively. After eight times of repeated alternate immunization, a lymphocyte suspension from the left popliteal lymph nodes was fused to FO myeloma cells (ATCC). Hybridomas were cultured in DMEM supplemented with 20\% FBS (Hyclone) and HAT component (Sigma-Aldrich), and the clonal selection was performed by enzyme-linked immunosorbent assay (ELISA) and flow cytometric analysis on the hDPCs or odontoblasts.

\section{Immunophenotyping}

Cells dissociated by enzyme-free dissociation solution (Millipore) were incubated with proper antibodies or hybridoma supernatants in PBS containing 1\% BSA on ice, followed by treatment with FITC-conjugated anti-mouse IgG (1:100, Santa Cruz) as the secondary antibody. Cells were analyzed by flow cytometry in FACSCalibur ${ }^{\text {rin }}$ (BD Biosciences). Antibody binding affinity was quantified by using WinMDI program.

\section{Antibody isotyping and antibody gene sequencing}

The immunoglobulin isotype of each mAbs was determined by the Mouse Immunoglobulin Isotyping Kit (BD Pharmingen), according to the supplier's protocol. Rat anti-mouse IgG1, IgG2a, IgG2b, IgG3, IgM, IgA, Igא, and Ig $\lambda$ were used for coating multi-well plate, and hybridoma supernatant was applied into each well. The reference immunoglobulin mixtures (BD Biosciences) 
were used as positive controls. HRP-labeled rat anti-mouse immunoglobulin was added into each well, and the isotype signals were determined by optical density of $450 \mathrm{~nm}$. For antibody gene sequencing, total RNA was extracted from hybridoma cells by Easy-spinTM Total RNA Extraction kit (Intron), and cDNA was synthesized by Maxime RT-PCR PreMix Kit (Intron). To sequence variable regions of antibody heavy and light chains, PCR primers were synthesized and used as described previously (Additional file 1: Table S1) [23]. PCR amplification of variable heavy and light chain genes was performed as followed: 1 cycle of $5 \mathrm{~min}$ at $94{ }^{\circ} \mathrm{C}, 30 \mathrm{cy}$ cles of $1 \mathrm{~min}$ at $94^{\circ} \mathrm{C}, 1 \mathrm{~min}$ at $45^{\circ} \mathrm{C}, 1 \mathrm{~min}$ at $72^{\circ} \mathrm{C}$, and the final cycle of $5 \mathrm{~min}$ at $72^{\circ} \mathrm{C}$. For heavy chain sequencing, two variable heavy chain forward primers were combined with an isotype-specific constant region reverse primer. For light chain sequencing, three $\mathrm{k}$ variable light chain forward primers were combined with the corresponding constant region reverse primer. The PCR products were cloned into pBluescript $\mathrm{KS}(+)$ vector, and sequencing was proceeded.

\section{Quantitative real-time PCR}

cDNA for quantitative real-time PCR (qRT-PCR) was synthesized by using the ReverTra Ace ${ }^{\mathrm{T} x}$ qPCR RT kit (Toyobo). The qRT-PCR was performed by using iTaq ${ }^{\text {tw }}$ Universal SYBR Green Supermix (Bio-Rad) system. Used primers are listed in Additional file 1: Table S2. The cycling parameters of qPCR were followed: 1 cycle for $30 \mathrm{~s}$ at $95^{\circ} \mathrm{C}, 40$ cycles for $15 \mathrm{~s}$ at $95^{\circ} \mathrm{C}$, and $1 \mathrm{~min}$ at $60^{\circ} \mathrm{C}$. During PCR, a dissociation curve was constructed in the range of 65 to $95^{\circ} \mathrm{C}$. The GAPDH was used as an internal control to normalize the variability in target gene expression. Primer information was mentioned in Additional file 1: Table S2. Statistical analyses on three readings were carried out using Student's $t$ test, and $p$ values of less than 0.05 were considered significant.

\section{Western analysis and immunoprecipitation}

Cells were lysed using 1\% NP-40 buffer $(20 \mathrm{mM}$ Tris- $\mathrm{HCl}, \mathrm{pH} 8.0,150 \mathrm{mM} \mathrm{NaCl}, 2 \mathrm{mM}$ EGTA, $2 \mathrm{mM}$ EDTA, 1\% NP-40, phosphatase/protease inhibitors). For western blot analysis, the lysates were separated on SDS-PAGE, transferred to a PVDF membrane (Millipore), and then probed with antibodies against DSPP, DMP-1, Smad1, p-Smad1/5/9, Smad3, p-Smad2/3, p-p38 (purchased by Cell Signaling), p38, ERK, and p-ERK (purchased by Santa Cruz), followed by treatment with IgG-HRP (Millipore). For immunoprecipitation of surface antigens, intact cells were labeled by EZ-Link Sulfo-NHSLC-Biotin (Thermo Scientific). Biotin-labeled cell extract was incubated with antibody, followed by pull-down with Protein G-agarose (Incospharm). The immunoprecipitants were separated SDS-PAGE, transferred to a PVDF membrane (Millipore), and then probed with streptavidin (Sigma). The antigenic molecules were visualized by using ECL Western Blotting Detection Kit (GE healthcare) on film or directly by Coomassie Brilliant Blue staining.

\section{Immunohistochemistry}

Human dental pulp tissue extracted from the third molar was fixed in $4 \%$ paraformaldehyde and was incubated in 30\% sucrose, after washing with PBS. Tissue was embedded in Tissue-Tek O.C.T (Optimal Cutting Temperature) Compound (Sakura Finetechnical Co) and cut into $10-\mu \mathrm{m}$-thick coronal sections. Endogenous peroxidase activity was inhibited by incubation with $0.3 \%$ $\mathrm{H}_{2} \mathrm{O}_{2}$ in PBS for $30 \mathrm{~min}$. The sections were incubated at $\mathrm{RT}$ for $1 \mathrm{~h}$ in blocking solution (5\% goat serum in PBS containing $0.1 \%$ Tween 20;0.1\% PBST) and treated with the antibody at $4{ }^{\circ} \mathrm{C}$ for $16 \mathrm{~h}$. Then, tissues washed for $0.1 \%$ PBST and incubated with biotin-conjugated anti-mouse IgG (Vector Laboratories) at RT for $1 \mathrm{~h}$. After washing, tissue sections were incubated with VECTASTAIN ABC Reagent (Vector Laboratories) at RT for 30 min and were incubated with the DAB substrate for the development of signals. Nucleus was detected by hematoxylin and eosin staining. Microscope slides were mounted in Eukitt quick-harder mounting medium (Sigma-Aldrich), and tissues were detected by the Upright FL microscope, Nikon Eclipse 80i (Nikon).

\section{Magnetic-activated cell sorting}

Cell sorting was performed using the magnetic-activated cell sorting (MACS) kit (Miltenyi Biotec) according to the manufacturer's instructions. Cells were dissociated by enzyme-free dissociation solution dissociation buffer (Millipore) and incubated with $100 \mu \mathrm{l}$ biotin-conjugated mAbs. Subsequently, cells were incubated with MACS MicroBeads (Miltenyi Biotec) and applied into a MACS column (Miltenyi Biotech), which placed in a MACS separator (Miltenyi Biotech). The mAb-positive cells were retained on the column, but negative cells were eluted in the flow-through fraction. For elution of positive fraction, the column was removed from the magnetic separator.

\section{Results}

Dentinogenic differentiation of human adult dental pulp cells by co-treatment of BMP2 and BMP4

To identify the optimal conditions for dentinogenic differentiation, human adult dental pulp cells were treated with various cytokines. TGF $\beta-1$ reportedly promotes odontoblastic differentiation of dental pulp cells, and its effect was synergistically increased by FGF2 [24, 25]. When hDPCs were co-treated with FGF2 and TGF $\beta-1$ in this study, the expression levels of odontogenic and 

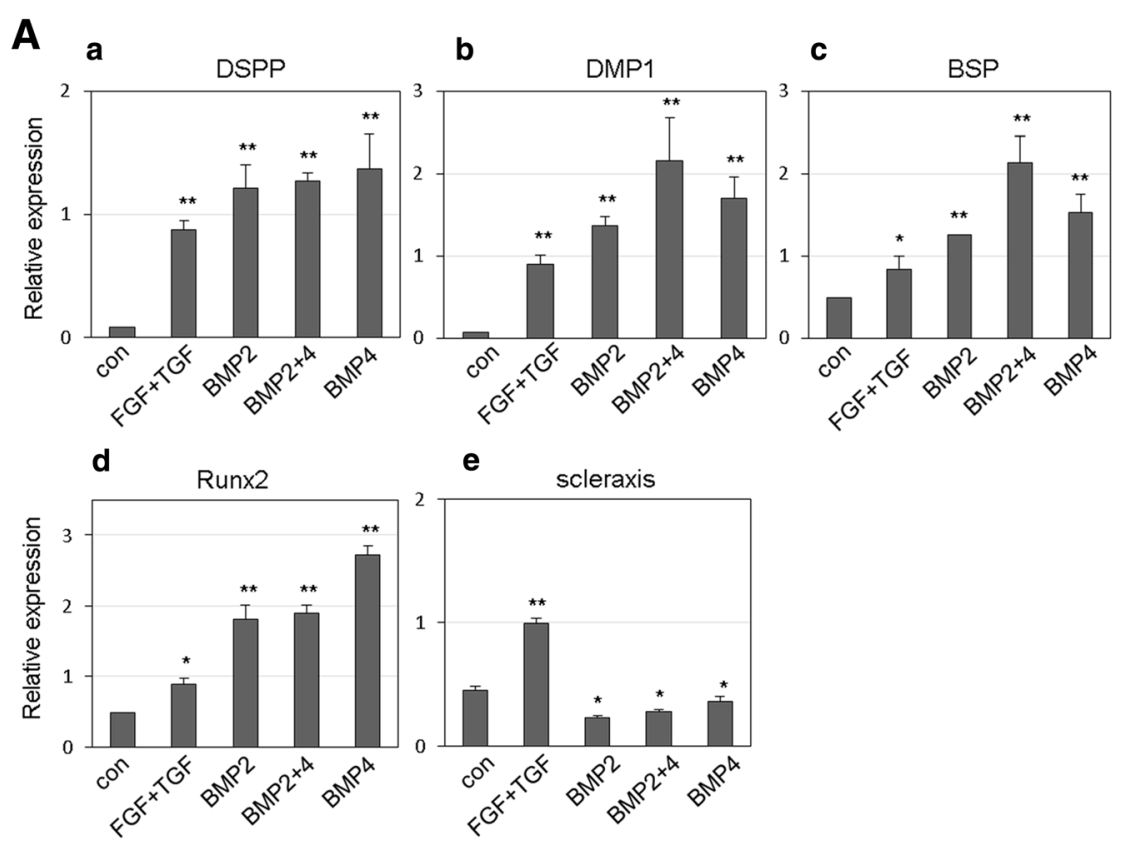

B b
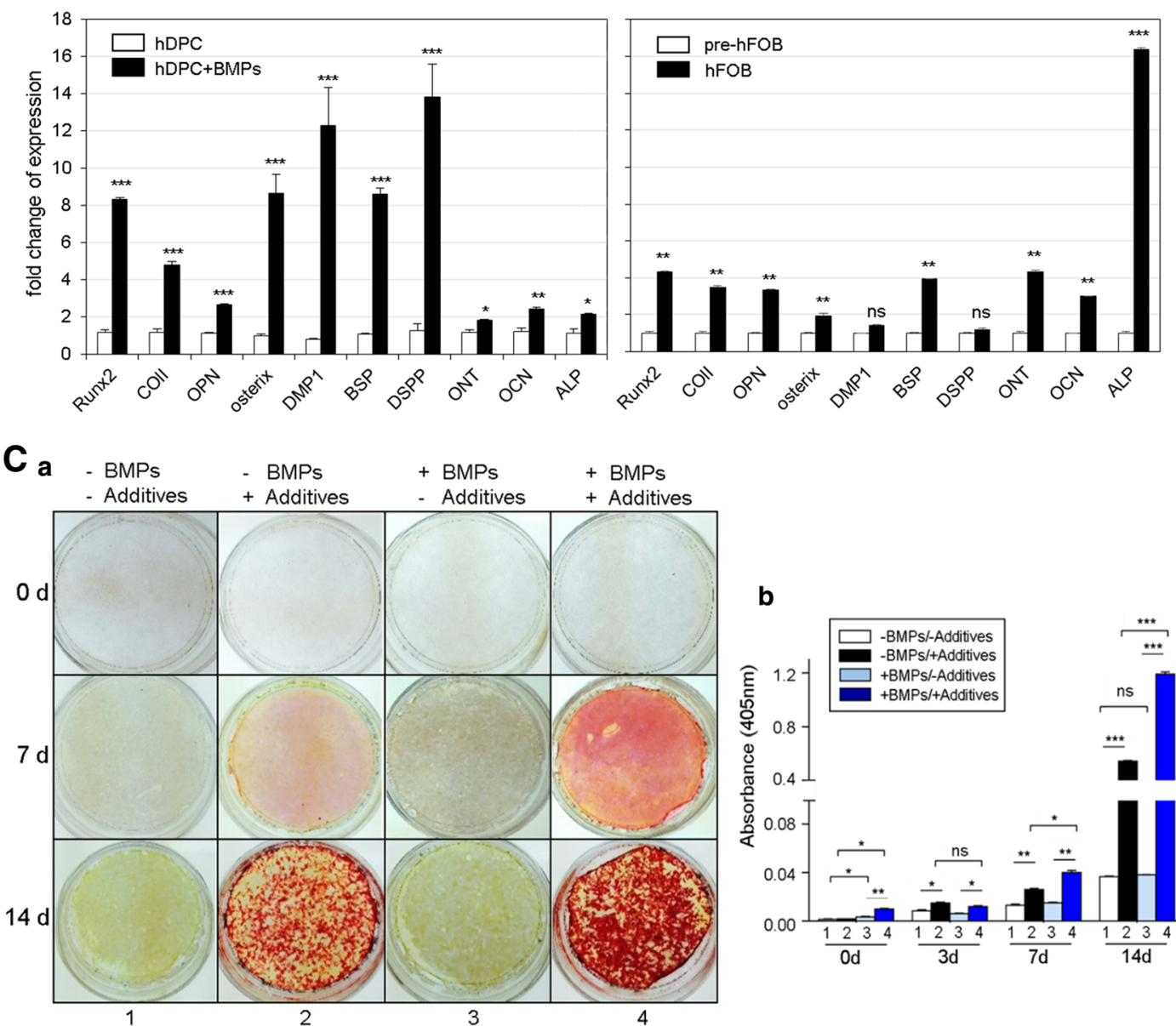

b

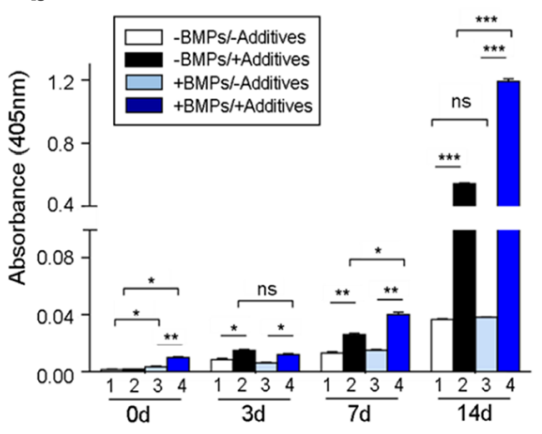

Fig. 1 (See legend on next page.) 
(See figure on previous page.)

Fig. 1 Co-treatment of BMP2 and BMP4 promotes the expression of odontoblast marker genes in hDPCs by induction of odontogenic cytodifferentiation. A Expression patterns of odontogenic and osteogenic markers by treatment with various cytokines. hDPCs were treated with $100 \mathrm{ng} / \mathrm{ml} \mathrm{FGF2}$ and $50 \mathrm{ng} / \mathrm{ml}$ TGF $\beta-1$ (FGF+TGF), $100 \mathrm{ng} / \mathrm{ml} \mathrm{BMP2} \mathrm{(BMP2),} 100 \mathrm{ng} / \mathrm{ml} \mathrm{BMP4} \mathrm{(BMP4),} \mathrm{or} 100 \mathrm{ng} / \mathrm{ml} \mathrm{BMP2}$ and $100 \mathrm{ng} / \mathrm{ml}$ BMP4 (BMP2+4). No treatment sample was indicated as con. B Comparison of expression patterns of odontogenic and osteogenic markers in between odontoblast-like cells (a) and osteoblasts (b) by co-treatment with BMP2 and BMP4. hDPC, human dental pulp cells no-treated with BMPs; hDPC +BMPs, human dental pulp cells co-treated with BMPs; pre-hFOB, human fetal osteoblasts grown at $34^{\circ} \mathrm{C}$; hFOB, human fetal osteoblasts grown at $39^{\circ} \mathrm{C}$ for induction of osteo-maturation. C Osteogenic/dentinogenic maturation efficiency is enhanced in hDPCs treated with BMP2 and BMP4. To induce mineral formation, cells were cultured in media containing mineralization additives for the indicated time, following BMPs treatment. Mineral formation on the cell surfaces was investigated by alizarin red S staining (a) under the microscope and was quantified as optical density at $405 \mathrm{~nm}$ (b). -BMPs/-Additives, hDPCs untreated; -BMPs/+Additives, hDPCs incubated in media containing mineralization additives; +BMPs/ -Additives, hDPCs treated with BMPs for odontogenic differentiation; +BMPs/+Additives, hDPCs incubated in media containing mineralization additives following BMPs treatment. Bar graphs represented the mean of three independent experiments \pm SD. Statistical data were analyzed by Student's $t$ test, and asterisk indicated the significant difference. ${ }^{* *}, P<0.001 ;{ }^{*}, P<0.01 ;{ }^{*}, P<0.05$; ns, not significant

osteogenic markers were increased compared to the controls (Fig. 1A, FGF+TGF in a-d). BMP2 treatment increased the expression levels of DSPP, DMP-1, BSP, and Runx2 by 14.1, 19.4, 2.6, and 3.8 times, respectively (Fig. 1A, BMP2 in $\mathrm{a}-\mathrm{d}$ ). In addition to BMP2, when hDPCs were treated with BMP4, the expression levels of DSPP, DMP-1, BSP, and Runx2 increased by 16.0, 24.3, 3.2, and 5.7 times, respectively (Fig. 1A, BMP4 in a-d). To investigate whether two BMPs exert a synergistic effect, hDPCs were co-treated with BMP2 and BMP4 (each $100 \mathrm{ng} / \mathrm{ml}$ ). Consequently, the expressions of DMP-1 and BSP increased to a greater extent than the individual treatments (Fig. 1A, b and $\mathrm{c}$ ). The expression of scleraxis, a marker of ligament differentiation, was induced by co-treatment with FGF2 and TGF $3-1$ and was decreased by BMP treatment (Fig. 1A, e).

To find optimal concentrations of BMP2 and BMP4 in dentinogenic differentiation, hDPCs were treated with a combination of various concentrations of two BMPs. The co-treatment of cells with $100 \mathrm{ng} / \mathrm{ml}$ BMP2 and 10 $\mathrm{ng} / \mathrm{ml} \mathrm{BMP} 4$ increased the mRNA expressions of genes to the highest levels (Additional file 1: Figure S1). To observe the difference of gene expressions during dentinogenesis and osteogenesis, two progenitor cells were prepared as followed: odontoblast-like cells were derived from hDPCs by co-treatment with BMP2 and BMP4 in a ratio of ten to one $(100 \mathrm{ng} / \mathrm{ml} \mathrm{BMP2}$ and $10 \mathrm{ng} / \mathrm{ml}$ BMP4) according to previous results, and osteoblasts were derived from pre-osteoblasts by incubation at restrictive temperature. In odontoblast-like cells, Runx2 and osterix levels were increased by 7.2 and 8.9 times than in dentinogenic induction, respectively (Fig. 1B, a). Similarly, DMP-1, DSPP, and BSP levels were highly increased by 16.0, 11.3, and 8.5 times in odontoblast-like cells, respectively (Fig. 1B, a). Although expression of alkaline phosphatase (ALP) was remarkably high in osteoblasts, no significant increase of expression of two dentin markers, DSPP and DMP-1, was observed in osteoblasts (Fig. 1B, b). These data indicate that the specific concentrations of BMP2 and BMP4 could maximize the efficiency of the dentinogenic differentiation of hDPCs and that the dentinogenic differentiation was totally discriminated with osteogenic differentiation in gene expressions. The phosphorylation of Smad1/5/9 was induced by BMP2 or BMP4 and increased further with co-treatment with two BMPs (Additional file 1: Figure S2), suggested that the co-treatment of hDPCs with BMP2 and BMP4 continue to activate the canonical BMP signaling at higher levels.

To investigate the mineralization efficiency, cells were incubated in media containing mineral-forming additives for the indicated times. hDPCs showed significantly less stained by alizarin red than odontoblast-like cells did after 7 days of mineralization induction (Fig. 1C, middle panels in 2 and 4 in a). After 14 days of mineralization induction, odontoblast-like cells showed a further darkened by alizarin red staining than hDPCs (Fig. 1C, lower panels in 2 and 4 in a and 14d in b). Although mineralization generally occurred after 14 days in hDPCs treated with additives, in case of odontoblast-like cells, mineral deposits were observed within 7 days of induction (Additional file 1: Figure S3). Like mineralization, ALP activity was increased by 1.3 times in odontoblast-like cells than in hDPCs (Additional file 1: Figure S4). These results suggested that co-treatment with BMP2 and BMP4 induce dentinogenic differentiation of hDPCs.

\section{Construction of a set of monoclonal antibodies against cell surface molecules of odontoblast-like cells}

For screening of the cell surface markers expressed specifically in odontoblast-like cells, we constructed hybridomas secreting monoclonal antibodies that specifically recognized odontoblast-like cells using an immunomic approach (see the "Methods" section, Fig. 2A). A total of 342 hybridomas were primarily selected. To confirm whether the monoclonal antibodies were specific for the odontoblast-like cells which were induced from hDPCs by treatment with BMPs, cell binding affinities were analyzed by flow cytometry. Twenty-nine of the mAbs 


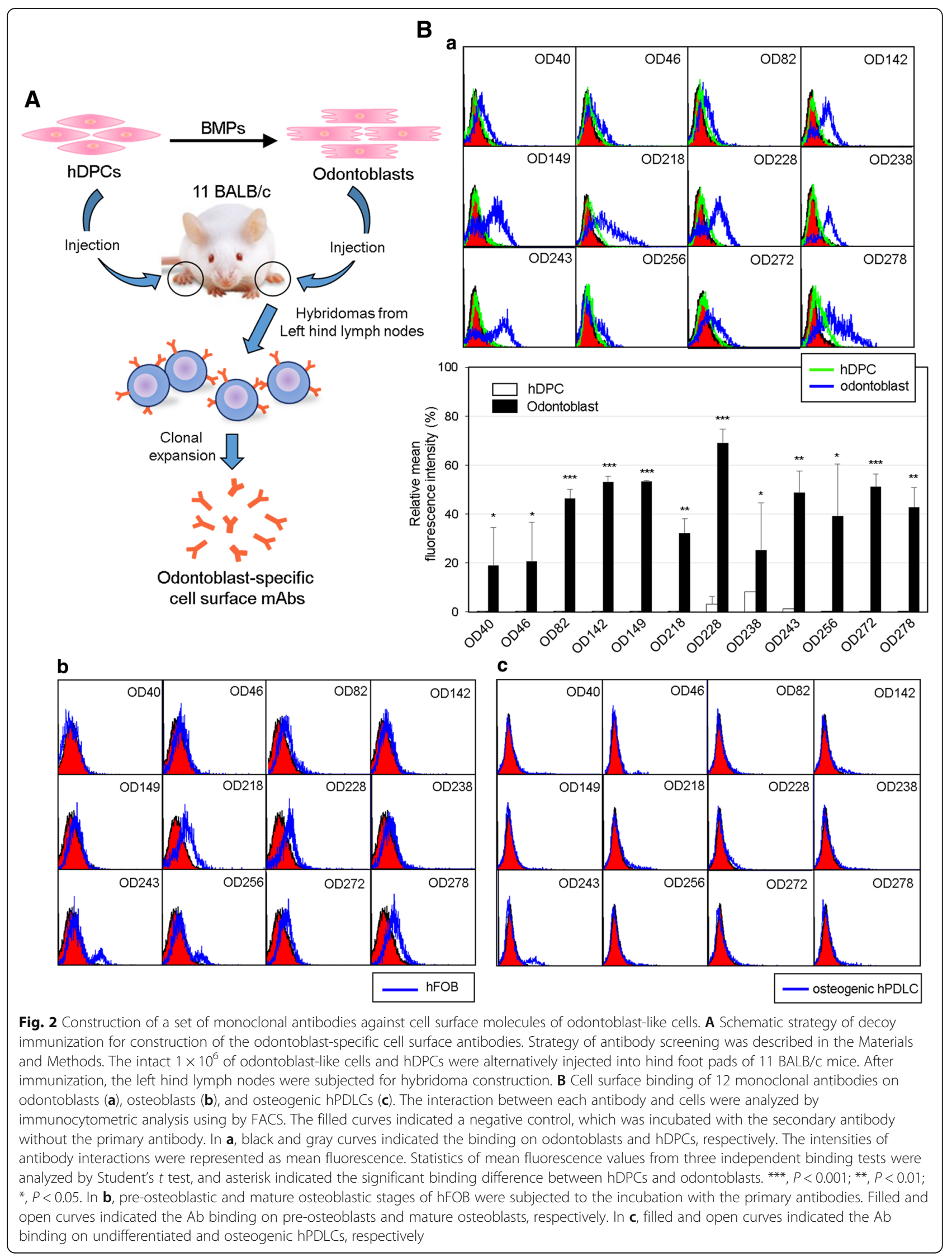




\begin{tabular}{|c|c|c|c|c|c|c|c|c|}
\hline \multirow[b]{3}{*}{ mAb } & \multicolumn{6}{|c|}{$\begin{array}{l}\text { Heavy } \\
\text { chain }\end{array}$} & \multicolumn{2}{|c|}{$\begin{array}{l}\text { Light } \\
\text { chain }\end{array}$} \\
\hline & \multicolumn{4}{|c|}{ IgG } & \multirow{2}{*}{$\lg M$} & \multirow{2}{*}{$\lg A$} & \multirow{2}{*}{ K } & \multirow{2}{*}{$\lambda$} \\
\hline & G1 & G2a & G2b & G3 & & & & \\
\hline OD40 & + & - & - & - & - & - & + & - \\
\hline OD46 & - & - & + & - & - & - & + & - \\
\hline OD82 & + & - & - & - & - & - & + & - \\
\hline OD142 & + & - & - & - & - & - & + & - \\
\hline OD149 & + & - & - & - & - & - & + & - \\
\hline OD218 & + & - & - & - & - & - & + & - \\
\hline OD228 & + & - & - & - & - & - & + & - \\
\hline OD238 & + & - & - & - & - & - & + & - \\
\hline OD243 & + & - & - & - & - & - & + & - \\
\hline OD256 & + & - & - & - & - & - & + & - \\
\hline OD272 & + & - & - & - & - & - & + & - \\
\hline OD278 & + & - & - & - & - & - & + & - \\
\hline
\end{tabular}

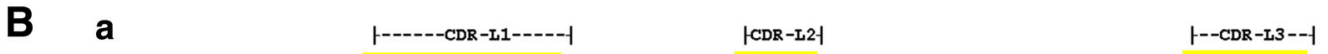

OD 40 QLTQS PASLSVVVGETVTITC RASENTYSHLA------ WYQERQGRSPQLLVY AATWLAD GVPSRFSGSGSGTQYSLKINRLQSEDEGSYYC QHFWGTLPT- FGGGPSERSG

OD 46 QLTQSPSSLAMSVGQKVTMSC KSSQSLINSSNQKNYLA WYQQKPGQS PKLLVY FASARKS GVDDRF IGSGSGTDFTLTISSVQAEDLADYFC QQHYTTPWTT- FGGGTKLNOTG

OD 82 QLTQS PALMSAS PGEKVTMTC SASSSVSYMN------- WYQRKPRSSPKPWIY LTSNLAS GVPARFSGSGSGTSYSLTISMMEAEDAATYYC QQWNSNPLT- FGAGPS

OD 142 QLTQS PKELIVSAGDRVTITC KASOSVSNDVA------ WYOOKPGOS PRLLTY YASURYT GVPDPFTGSGYGTDETETINTMOAEDLAVYFC QQDDYSSPYT- FGGGTKLEIKRADAAPTVS

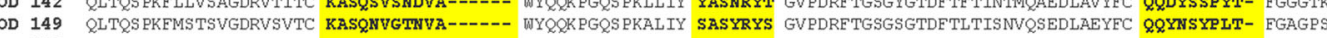

OD 218 QLTQS PAILSAEPGEKVTMTC RASSSVSYMN------- WYOOKPGSSERPWIY ATSNLAS GVPARFSGSGSGASYSLTISRVEAEDAATYYC QQWWSWMPYT FGGGP

OD 228 VLTQS PASLAVSAGEKVTMSC KSSQSVLYSSNOKNYLA WYQRKRGQS SKLLIY WASTRES GVPDRETGSGSGTDETLTISSVQAEDLAVYYC HQYLSWT--- FGGGTKLEIKRADAAPTVS

OD 238 QLTTS PSSLAMSVGOKVTMSC KSSQSLINSSNQKNYLA WYQQKPGQS PKLLVY FASXRKS GVPDRE IGSGSGTDETLTISSVQAEDLADYFC QQHYYTTPWT- FGGGTKLNQSWM

OD 243 QLTRSPSSLSASLGDRVTISC RASLDISNYLN------ WYQRKPDGTVKLLTY YTSRLHS GVPSRFSGSGSGTDYSLTISNLDQEDFATYFC QQQGNTLPWT- FGGGTKLEIKRADAAPTVS

OD 256 QLTQS PLSLPVSLGDQASISC RSSQSLVHSNGNTYLH - WYLQK PGQSPKLLIY KVSNRES GVPDRENGSGSGTDFTLKISRVEAEDLGVYFC SQSTHVPFT- FGSGTELEIKRADAAPTVS

OD 272 QLTQS PSSLAMSVGQKVTMSC KSSQSLINSSWQKNYLA WYQ尺K PGQS PRLLVY FASARKS GVDDRFIGSGSGTDETLTISSVQAEDLADYFC QQHYTTPWT- FGGGTKLNQAG

OD 278 SADPVSKEMSTSVGDRVSITC KASQDVSTTVA----- WYQRKRGQS SKLLIY WASTRHT GVDDRETGSGSGTDYSLTISSVQAEDLALYYC QRHYSTPYT- FGGGTKLEIKRADAAPTVS

b

--CDR-H1--1

1------CDR-H2-------1

1-------CDR-H3------1

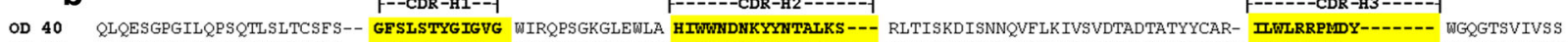
OD 46 QLQQSGAELVRPGSSVKISCKAS-- GYAFSSYWNN-- WVKORPGQGLEWIG QIYPGDGDSNYNGKFKG-- KATLTADKSSS IAYMOLSSLTSEDSAVYFCARF GSTATADY-------- WGQGTTLTVSSA

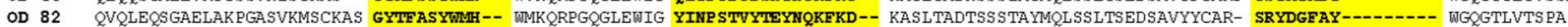

OD 142 QLOOSGGGLVK PGGSLKLSCAAS-- GFTFSSYAUS -- WVROTPERRLEWVVA TISSGGSYTYYPDSVKG-- RFTTSRDNAKNTLYLOMSSLRSEDTAMYYCAR- RSYDGGGVWFAY----- WIGQGTLVTST

OD 149 OLOESGTELVRPGA.SVKLSCKAI-- GYTF TDYEMH-- WVKOTPVHGLEWTG ATHPGSGGTPYYONFRG-- KATLTADKSSSTAYMELSSLTSEDSAVYYCTT- YGNYFDY--------- WTSGTTLTVST

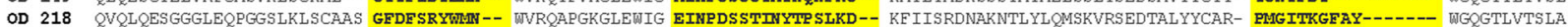

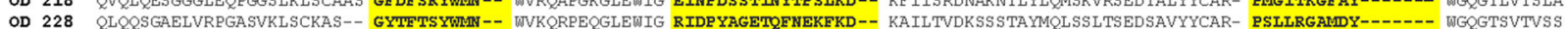

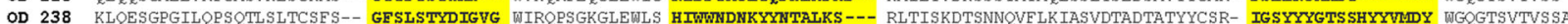

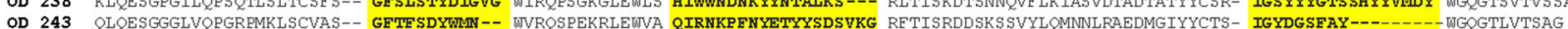

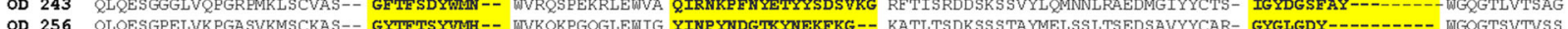

DD 272 OLPCG

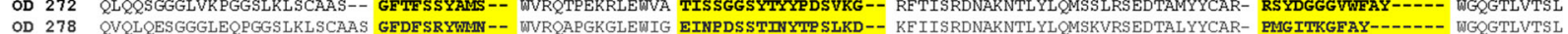

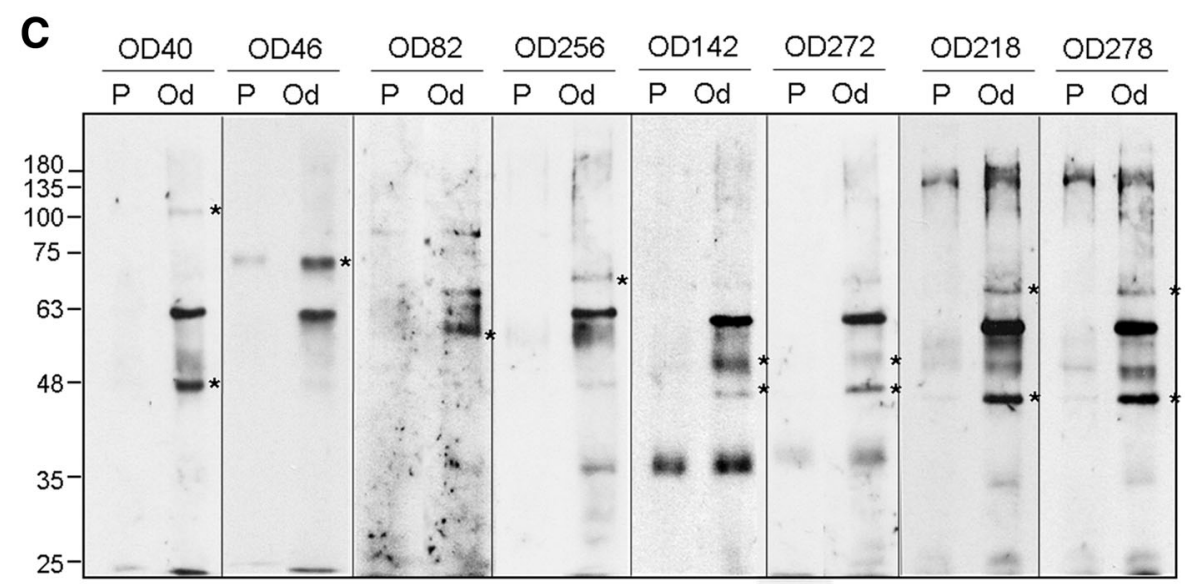

Fig. 3 (See legend on next page.) 
(See figure on previous page.)

Fig. 3 Characterization of 12 lgG-type monoclonal antibodies. A Isotypes of 12 mouse lgG-type monoclonal antibodies (lgG1, lgG2a, lgG2b, lgG3, and kappa/lambda) derived from hybridoma supernatant of the 12 clones. B Amino acid sequences of mouse immunoglobulin heavy and light chain variable regions of $12 \mathrm{mAbs}$. PCR fragments of heavy and light chain variable region genes were amplified from cDNA derived from hybridoma clones by using IgG variable region-based degenerate PCR primers as shown in Additional file 1: Table S1. The consensus sequences of lgG light chain (a) and IgG heavy chain (b) of variable regions were compared. Three complementarity determining regions in light and heavy chains (CDR-L1-3 and CDR-H13) were shown in shading boxes. $\mathbf{C}$ Identification of the antigenic molecules recognized by representative mAbs. Cell surface were biotinylated and antigenic molecules were captured by mAb. These molecules were visualized by western blot using streptavidin-HRP

bound to odontoblast-like cells more specifically than they did to hDPCs, and 17 and 12 of total 29 mAbs turned out to be IgM and IgG types, respectively. Only IgG types were studied further in this study. Eight mAbs appeared to be more specific to odontoblast-like cells (OD142, OD149, OD218, OD228, OD238, OD243, OD272, and OD278); of these 12, four clones bound much more weakly (OD40, OD46, OD82, and OD256) (Fig. 2B, a). To compare the antibody binding affinity in odontoblasts and osteoblasts, cell bindings of the mAbs on the hFOB and the osteogenic hPDLCs were investigated. The osteogenic differentiation of hPDLCs was confirmed by expression of the osteogenic markers (Additional file 1: Figure S5). Cell binding affinities of the mAbs for both osteoblasts were generally lower than they were for odontoblast-like cells (Fig. 2B, b and c). In addition, these antibodies were not interacted with fibrogenic and epithelial osteosarcoma cell lines such as MG63 and Saos-2, respectively (Additional file 1: Figure $\mathrm{S6}$, a \& b). These results suggested that $12 \mathrm{mAbs}$ constructed in this study specifically recognize odontoblast-like cells. Immunoglobulin subclass of the 11 IgG clones was the IgG1 type, and the OD40 clone was the IgG2b type. All hybridoma clones contained the kappa-type light chain (Fig. 3A). In all cases, the core sequences in three CDRs of the heavy and light chains were conserved (Fig. 3B). Interestingly, OD142 and OD272 or OD218 and OD278 contained the same amino acid sequences of the heavy chain CDR regions (Fig. 3B, b), whereas their light chain CDR regions were completely different (Fig. 3B, a). To detect the antigenic molecules recognized by mAbs, we performed immunoprecipitation with biotin-labeled hDPCs and odontoblastic cells using the representative antibodies (Fig. 3C). Interestingly, the antigenic molecules immunoprecipitated by OD142 and OD272 or OD218 and OD278 were considered as the same molecules in odontoblast-like cells, respectively. Together with CDR sequences, these data suggested that these antibodies recognized the different epitopes of the same antigenic molecules.

\section{Monoclonal antibodies recognize the odontogenic differentiation of hDPCs in vivo and in vitro} The mAbs OD40, OD46, OD82, OD142, OD149, OD218, OD228, OD238, OD243, OD272, and OD278 mainly recognized the odontoblastic layer regions (Additional file 1: Figure S7, Od) of the dental pulp tissue in human tooth wherein odontoblasts were concentrated, and mAb OD256 strongly detected the perivascular regions in pulp core (Fig. 4A and Additional file 1: Figure S7, P). These results suggested that the mAbs identified were specific for odontoblastic cells in vivo. To confirm the specificity of these antibodies in the stage of the differentiation process, the binding affinity of mAbs were analyzed in hDPCs, in odontoblast-like cells, and in mature dentin-forming cells. Dentin maturation stage was induced by treatment with mineralization additives for 7 days. Although the expressions of Runx2, osteopontin, BSP, osteonectin, osteocalcin, and ALP increased gradually during maturation, those of collagen type-1, osterix, DMP-1, and DSPP, which were expressed in odontoblast-like cells specifically, decreased during mineralization (Additional file 1: Figure S8, gray and black bars in a). Stro-1, CD44, and CD73 are general surface markers for mesenchymal stem cells, and they were also expressed in dental stem cells [21]. Although Stro-1 expression was higher in odontoblast-like cells than in hDPCs, the expression of CD44 and CD73 was decreased in these cells. With dentinogenic maturation, the expression of Stro- 1 and CD44 markers was much decreased (Fig. 4B, Stro-1, $\mathrm{CD} 44$, and CD73). The expression of CD24, a negative marker, was not detected in the cells at any stage (Fig. 4B, CD24). Cell surface binding of $12 \mathrm{mAbs}$ was rarely detected in the undifferentiated hDPCs (Fig. 4B, panel 1 in a) and was dramatically increased in odontoblast-like cells derived from hDPCs after treatment with BMPs (Fig. 4B, panel 2 in a). After a 7-day induction of mineral formation, cell binding affinities of mAbs were decreased (Fig. 4B, panel 3 in a). Although surface expression of the OD40 and OD218 antigens was highly increased in odontoblast-like cells, its expression was remained stable during mineralization (Fig. 4B, OD40 and OD218 in a and b). These results indicated that mAbs identified in this experiment were useful to detect odontoblastic cytodifferentiation of hDPCs, and their binding affinities on the cell surface were decreased during mineral formation in dentinogenic maturation. 


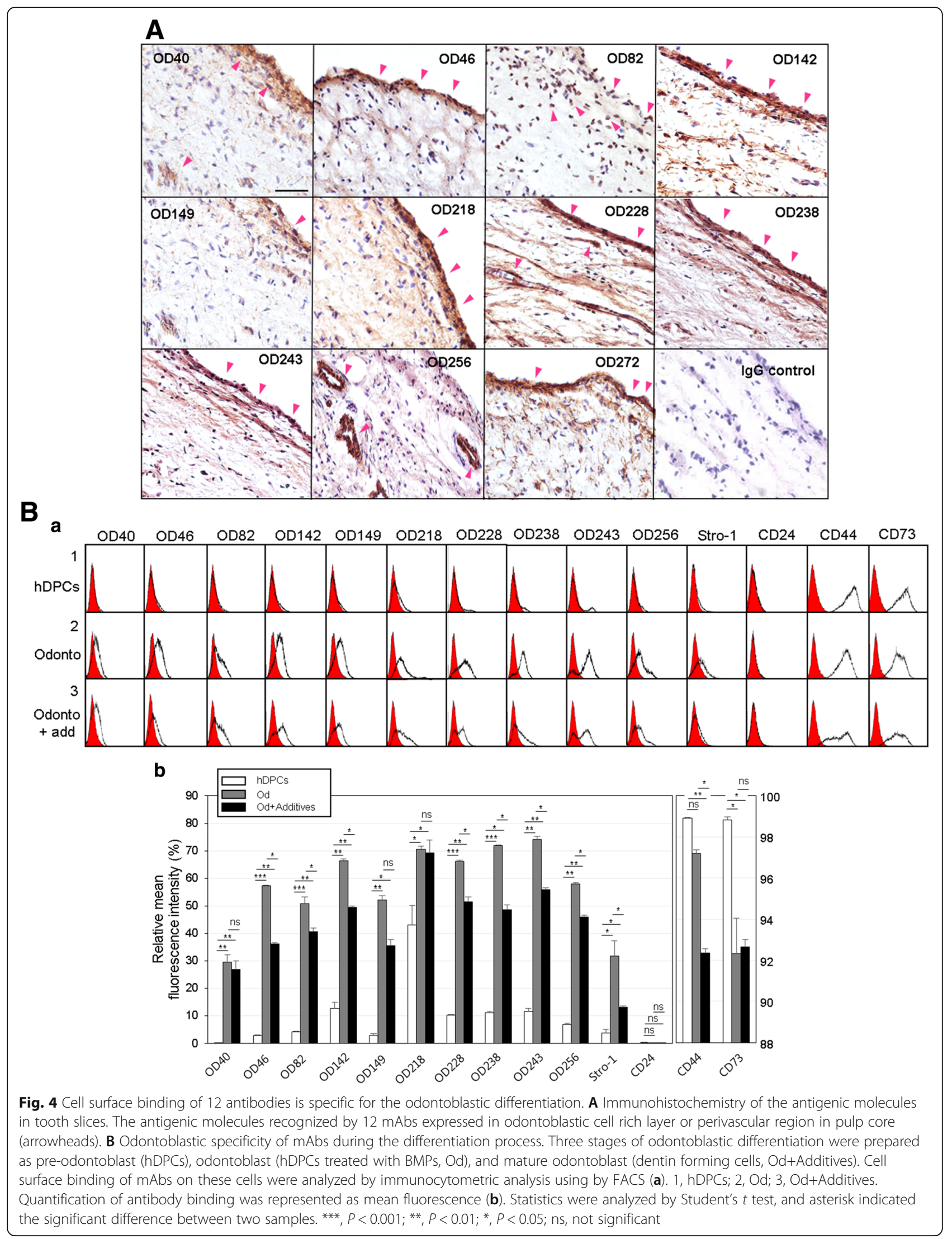


Identification of antigenic molecules: candidates for odontoblast-specific cell surface and extracellular matrix molecules

We first identified the antigenic molecules against the mAbs OD40 and OD46. The immunoprecipitates of OD40 and OD46 antigens were detected on SDS-PAGE by Coomassie blue staining. The bands of $180,90,55$, and $50 \mathrm{kDa}$ in OD40 immunoprecipitant and 70, 55, 50, and $25 \mathrm{kDa}$ in OD46 immunoprecipitant were detected, and their amino acid sequences were analyzed by tandem mass spectrometry (Additional file 1: Figure S9 \& S10, arrowheads and asterisks in a). As a result of tandem mass analysis, the $90 \mathrm{kDa}$ and $70 \mathrm{kDa}$ molecules were found to be leprecan-1 and annexin-A6/Calelectrin as the specific antigens of OD40 and OD46 antibodies, respectively (Additional file 1: Figure $S 9 \& S 10, b)$. The other bands were found to be the mouse IgG. The OD40 antigen leprecan-1 is a basement membrane-associated chondroitin sulfate proteoglycan, which is involved in the collagen secretory pathway of cells [26]. The OD46 antigen annexin A6/Calelectrin is a member of the annexin family, which is involved in many aspects of cellular membrane dynamics and in the regulation of membrane-associated proteins [27].
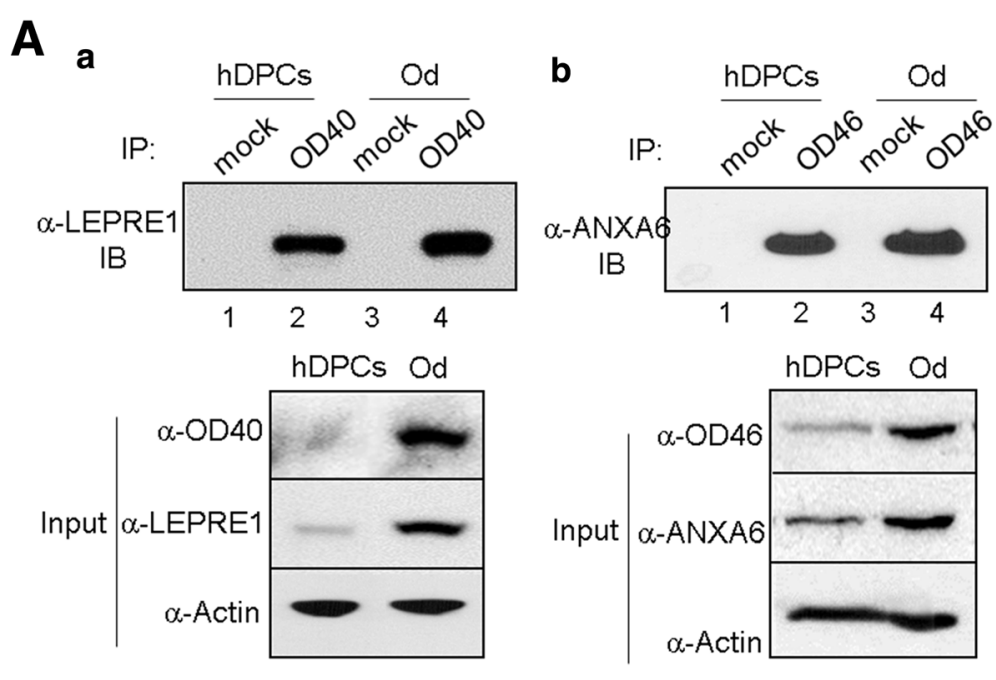

B

a

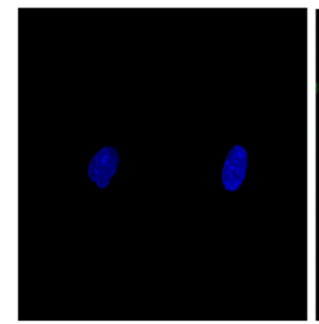

$\alpha-O D 40$

merge
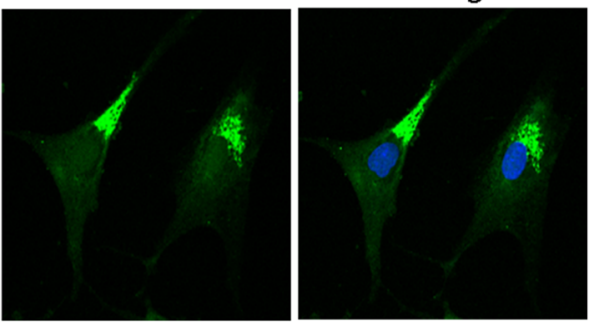

DAPI

$\alpha-\mathrm{OD} 46$

merge
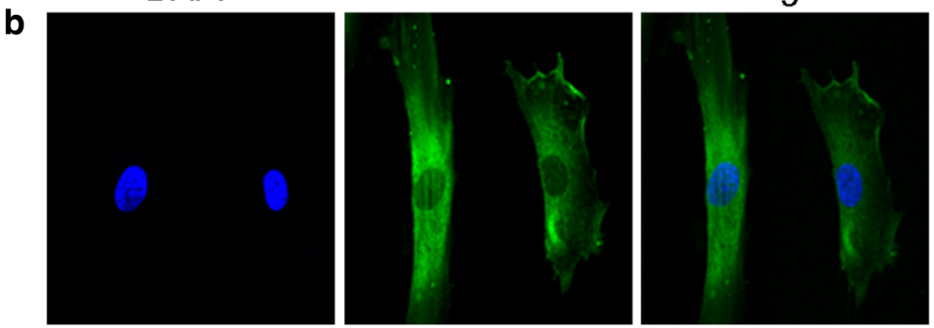

Fig. 5 Antigen identification of two representative surface molecules recognized by mAb OD40 and OD46. A Antigenic molecules in the immnoprecipitants of OD40 (a) and OD46 (b) were applied to western blot (IB) with anti-leprecan-1 and anti-annexin A6 antibodies, respectively. Endogenous protein amounts were indicated in input panels. 1 and 3, IP with mouse IgG; 2 and 4, IP with mAbs. B Subcellular localization of the antigenic molecules against mAbs in the odontoblast-like cells. 1, nuclei stained by DAPI; 2, treatment with the primary mAbs and FITC-labeled secondary antibody; 3, merge with 1 and 2 . Bar indicates as $100 \mu \mathrm{m}$ 
Indeed, anti-leprecan-1 and anti-annexin A6 antibodies showed strong cross-activity to the antigenic molecules OD40 and OD46 (Fig. 5A, a and b). As expected, the endogenous amounts of these molecules increased more in odontoblast-like cells than in hDPCs (Fig. 5A, input in a and b). By immunofluorescence analysis, the antigenic molecules against mAbs identified were localized to the cell surface or inner membrane structures (Fig. 5B). In addition to OD40 and OD46, other representative antigenic molecules also were detected in the similar subcellular localization patterns (Additional file 1: Figure S11). These data suggested that these antigenic molecules are the candidates of cell membrane and extracellular matrix components of odontoblast-like cells. To investigate the sorting potential of two antibodies, unsynchronous hDPCs and odontoblasts were separated by magnetic-activated cell sorting technique using these mAbs, and the antibody-cell binding affinities were confirmed through FACS analysis. A significant antibody binding disappeared in the fractions of flow-through (Fig. 6A, panel 2 in a and b). Based on quantification, the relative mean fluorescence intensities of the $\mathrm{mAb}$
OD40- and OD46-positive cells were increased in 7.5 and 3.1 times than in the negative cells, respectively (Fig. 6, panel 3 in A and B). Mineralization efficiency was highly increased in 1.75 and 2.35 times in the OD40- and OD46-positive cells, respectively (Fig. 6C).

\section{Discussion}

In adult tissues, stem cells are usually in a dormant state and divide and generate a progeny of undifferentiated cells to retain their stemness by self-renewal. Stem cells live in a specialized microenvironment, called "niche," which is highly specialized for each type of stem cell [28]. Niches comprise stem cells, supportive stromal cells, and the extracellular cellular matrix (ECM) wherein the stem cells are located [29]. They support stem cell survival and regulate stem cell behaviors, such as quiescence, self-renewal, and differentiation. The niche components influence the stem cell behavior and the interactions between stem cells and their niche are reciprocative, since stem cells are able to remodel the niche and secrete ECM components. Interactions between ECM and stem cells are directly mediated by

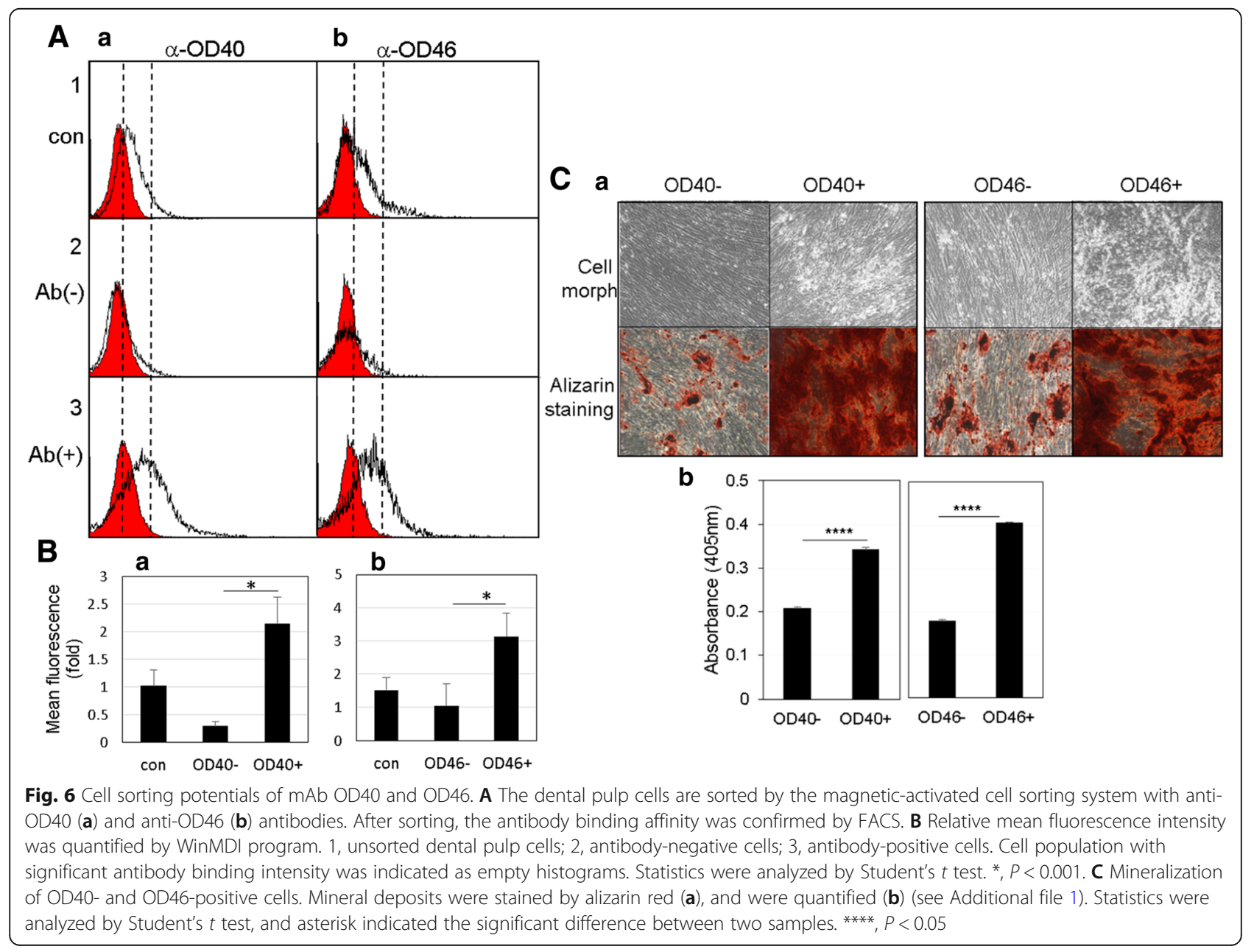


numerous cell receptors, including integrins and other cell membrane molecules. These are the key heterodimeric transmembrane receptors involved in the connection of the extracellular environment to the intracellular cytoskeleton, thus mediating cell migration, proliferation, survival, and differentiation. Since integrins and other cell membrane molecules can also regulate signaling pathways in response to growth factors and cytokines [30] and signaling pathways can conversely regulate integrin expression, the specific activities of these ECM receptors are required to determine a particular type of stem cells [31]. Dental pulp stem cells derived from adult dental pulp tissue are reportedly a suitable cell source for regenerative dentistry. In dentin-pulp regeneration, it is important to enhance the odontoblastic differentiation potential of DPSCs. BMPs (e.g., BMP2, BMP4, and BMP7), TGF $\beta-1$, FGFs, and VEGF have long been known to be incorporated into dentinogenesis in several previous reports [32, 33], and in this study, the combination treatment of BMP2 and BMP4 was the most effective in the induction of odontoblast-like cells from hDPCs (Fig. 1). Although cytokines for odontogenic induction are relatively well known, little was known about cell surface molecules and ECM for odontogenic niches. Two ECM molecules, DMP-1 and MEPE, are known as key molecules that play a regulatory role in the odontogenic induction of DPSCs $[34,35]$. In this study, we focused on the identification of novel odontoblast-specific cell surface molecules, which can be present in the odontogenic environment. Thus far, for identifying cell surface markers, proteomic approaches coupled with mass spectrometry have generally been used [36, 37]. In this study, we performed decoy immunization using intact odontoblast-like cells because this method has the advantage of immediate providing specific antibodies useful for direct recognition of the cell surface molecules. We showed that $12 \mathrm{mAbs}$ of IgG type obtained from 342 hybridomas specifically bound to odontoblast-like cells but not to hDPCs or osteoblasts (Figs. 2 and 4). Indeed, two of them tuned out to be a cell surface protein and an ECM component, and they specifically recognize in odontoblastic differentiation state (Fig. 5). In addition to OD40 and OD46, other antigenic molecules were localized in cell surface and inner secretory structures (Additional file 1: Figure S9). Taken together, we need further functional analysis, and the knowledge of these antigens can be useful in future studies on the regulation of cytodifferentiation of hDPCs and for understanding specific niches inducing odontogenic differentiation. More directly, mAbs can be applied to the detection and separation of odontoblastic cells from pulp tissue or undifferentiated hDPCs. Finally, these results suggest the immense potential of the construction of the effective odontogenic scaffolds using these cell surface/ECM-related antigens.

\section{Conclusions}

This study has conducted a screening of human odontoblast-specific cell surface monoclonal antibodies (mAbs) through decoy immunization with intact odontoblast-like cells. For this, human odontoblasts were obtained from adult dental pulp cells through dentinogenic differentiation by co-treatment with BMP2 and BMP4. These mAbs accumulated in the odontoblastic layer and perivascular region in the pulp core in the tooth. Antigenic expression increased during odontogenic cytodifferentiation and had the potential to be components for membrane and extracellular matrix. These mAbs will be helpful for detecting odontoblasts and for providing information on cell adhesion and microenvironment during dentinogenesis.

\section{Additional file}

Additional file 1: Additional Information for Materials and Methods. Table S1. Oligonucleotide primers used for antibody sequencing. Table S2. Oligonucleotide primers used for quantitative real-time PCR. Figure S1. Expression patterns of odontogenic and osteogenic markers by cotreatment with BMP2 and BMP4. Figure S2. BMP2 and/or BMP4 stimulation activate the Smad1/5/9 signal pathway. Figure S3. Osteogenic/dentinogenic maturation efficiency is enhanced in hDPCs treated with BMP2 and BMP4. Figure S4. Osteogenic/dentinogenic maturation efficiency is enhanced in hDPCs treated with BMP2 and BMP4. Figure S5. Odonto/ osteoblastic marker expressions in hPDLCs. Figure S6. Cell surface bindings of 12 monoclonal antibodies on MG63 (a) and Saos-2 (b). Figure S7. Structure of human tooth. Figure S8. Odonto/osteoblastic marker expressions during the differentiation process. Figure S9. Antigen identification of surface molecules recognized by mAb OD40. Figure S10. Antigen identification of surface molecules recognized by mAb OD46. Figure S11. Subcellular localization of the antigenic molecules against the representative mAbs in the odontoblast-like cells. (DOCX 3604 kb)

\section{Abbreviations}

ALP: Alkaline phosphatase; BMP: Bone morphogenic proteins; BSP: Bone sialoprotein; DMP-1: Dentin matrix protein-1; DSPP: Sialophosphoprotein; ECM: Extracellular matrix; hDPCs: Human dental pulp cells; hFOB: Human fetal osteoblast; hPDLCs: Human periodontal ligament cells;

mAb: Monoclonal antibody; SDS-PAGE: Sodium dodecyl sulfatepolyacrylamide gel electrophoresis

\section{Acknowledgements}

We thank Dr. Lee Jae-Hoon in Dankook Dental Hospital and Dr. Lee Kyu-Tae in Yonsei Wooil Dental Hospital for Provision of research materials. We also thank Dr. Sun-Yi Hyun and Dr. Hyun Min Lee for technical supports of antibody development.

\section{Funding}

This research was supported by the Bio \& Medical Technology Development Program of the NRF funded by the Korean government, MSIP (NRF2015M3A9(6029130).

\section{Availability of data and materials}

The datasets used and analyzed during the current study are available from the corresponding author on reasonable request. 


\section{Authors' contributions}

KJK contributed to the collection, analysis, and interpretation of data. CJR contributed to the conception and design of data. YJJ is responsible for conception and design of data, analysis and interpretation of data, manuscript writing, and final approval of the manuscript. All authors read and approved the final manuscript.

\section{Ethics approval and consent to participate}

Not applicable

\section{Consent for publication}

Not applicable

\section{Competing interests}

The authors declare that they have no competing interests.

\section{Publisher's Note}

Springer Nature remains neutral with regard to jurisdictional claims in published maps and institutional affiliations.

\section{Author details}

'Department of Nanobiomedical Science and BK21 PLUS Global Research Center for Regenerative Medicine, Dankook University, Cheonan 31116, South Korea. ${ }^{2}$ Department of Integrative Bioscience and Biotechnology, Institute of Anticancer Medicine Development, Sejong University, Seoul 05006, South Korea.

\section{Received: 22 January 2019 Revised: 5 April 2019}

\section{Accepted: 8 April 2019 Published online: 27 April 2019}

\section{References}

1. Gronthos S, Mankani M, Brahim J, Robey PG, Shi S. Postnatal human dental pulp stem cells (DPSCs) in vitro and in vivo. Proc Natl Acad Sci U S A. 2000; 97(25):13625-30

2. Miura M, Gronthos S, Zhao M, Lu B, Fisher LW, Robey PG, et al. SHED: stem cells from human exfoliated deciduous teeth. Proc Natl Acad Sci U S A. 2003;100(10):5807-12.

3. Huang GT, Gronthos S, Shi S. Mesenchymal stem cells derived from dental tissues vs. those from other sources: their biology and role in regenerative medicine. J Dent Res. 2009;88(9):792-806.

4. Thesleff I, Mikkola M. The role of growth factors in tooth development. Int Rev Cytol. 2002:217:93-135.

5. Tummers $M$, Thesleff I. The importance of signal pathway modulation in all aspects of tooth development. J Exp Zool Part B. 2009:312B(4):309-19.

6. Iohara K, Nakashima M, Ito M, Ishikawa M, Nakasima A, Akamine A. Dentin regeneration by dental pulp stem cell therapy with recombinant human bone morphogenetic protein 2. J Dent Res. 2004;83(8):590-5.

7. Chen S, Gluhak-Heinrich J, Martinez M, Li T, Wu Y, Chuang HH, et al. Bone morphogenetic protein 2 mediates dentin sialophosphoprotein expression and odontoblast differentiation via NF-Y signaling. J Biol Chem. 2008; 283(28):19359-70.

8. Cho YD, Yoon WJ, Woo KM, Baek JH, Park JC, Ryoo HM. The canonical BMP signaling pathway plays a crucial part in stimulation of dentin sialophosphoprotein expression by BMP-2. J Biol Chem. 2010;285(47): 36369-76.

9. Feng JS, Yang GB, Yuan GH, Gluhak-Heinrich J, Yang W, Wang L, et al. Abnormalities in the enamel in Bmp2-deficient mice. Cells Tissues Organs. 2011;194(2-4):216-21.

10. Yang W, Harris MA, Cui Y, Mishina Y, Harris SE, Gluhak-Heinrich J. Bmp2 is required for odontoblast differentiation and pulp vasculogenesis. J Dent Res. 2012;91(1):58-64.

11. Wu L, Wang F, Donly KJ, Wan CY, Luo DS, Harris SE, et al. Establishment of immortalized mouse Bmp2 knock-out dental papilla mesenchymal cells necessary for study of odontoblastic differentiation and odontogenesis. Cell Physiol. 2015;230(11):2588-95.

12. Hassan MQ Tare RS, Lee SH, Mandeville M, Morasso Ml, Javed A, et al. BMP2 commitment to the osteogenic lineage involves activation of Runx2 by DLX3 and a homeodomain transcriptional network. J Biol Chem. 2006; 281(52):40515-26
13. Matsubara T, Kida K, Yamaguchi A, Hata K, Ichida F, Meguro H, et al. BMP2 regulates Osterix through Msx2 and Runx2 during osteoblast differentiation. J Biol Chem. 2008;283(43):29119-25.

14. Bei M, Kratochwil K, Maas RL. BMP4 rescues a non-cell-autonomous function of Msx1 in tooth development. Development. 2000;127(21):4711-8.

15. Jia S, Zhou J, Gao Y, Baek JA, Martin JF, Lan Y, et al. Roles of Bmp4 during tooth morphogenesis and sequential tooth formation. Development. 2013; 140(2):423-32.

16. Kwon HE, Jia S, Lan Y, Liu H, Jiang R. Activin and Bmp4 signaling converge on Wnt activation during odontogenesis. J Dent Res. 2017;96(10):1145-52.

17. Ye L, MacDougall M, Zhang SB, Xie YX, Zhang JH, Li ZB, et al. Deletion of dentin matrix protein-1 leads to a partial failure of maturation of predentin into dentin, hypomineralization, and expanded cavities of pulp and root canal during postnatal tooth development. J Biol Chem. 2004;279(18):19141-8.

18. Yang XC, van den Dolder J, Walboomers XF, Zhang WB, Bian Z, Fan MW, et al. The odontogenic potential of STRO-1 sorted rat dental pulp stem cells in vitro. J Tissue Eng Regen Med. 2007;1(1):66-73.

19. Yang XC, Walboomers XF, van den Beucken JJJP, Bian ZA, Fan MW, Jansen JA. Hard tissue formation of STRO-1-selected rat dental pulp stem cells in vivo. Tissue Eng Pt A. 2009;15(2):367-75.

20. Yasui T, Mabuchi Y, Toriumi H, Ebine T, Niibe K, Houlihan DD, et al. Purified human dental pulp stem cells promote osteogenic regeneration. J Dent Res. 2016;95(2):206-14

21. Hwang HI, Lee TH, Kang KJ, Ryu CJ, Jang YJ. Immunomic screening of cell surface molecules on undifferentiated human dental pulp stem cells. Stem Cells Dev. 2015;24(16):1934-45.

22. Hwang HI, Lee $T H$, Jang YJ. Cell proliferation-inducing protein 52 /mitofilin is a surface antigen on undifferentiated human dental pulp stem cells. Stem Cells Dev. 2015;24(11):1309-19.

23. Wang Z, Raifu M, Howard M, Smith L, Hansen D, Goldsby R, et al. Universal PCR amplification of mouse immunoglobulin gene variable regions: the design of degenerate primers and an assessment of the effect of DNA polymerase $3^{\prime}$ to 5' exonuclease activity. J Immunol Methods. 2000;233(1-2):167-77.

24. He H, Yu J, Liu Y, Lu S, Liu H, Shi J, et al. Effects of FGF2 and TGFbeta1 on the differentiation of human dental pulp stem cells in vitro. Cell Biol Int. 2008;32(7):827-34

25. Melin M, Joffre-Romeas A, Farges JC, Couble ML, Magloire H, Bleicher F. Effects of TGFbeta1 on dental pulp cells in cultured human tooth slices. J Dent Res. 2000;79(9):1689-96.

26. Kaul SC, Sugihara T, Yoshida A, Nomura H, Wadhwa R. Gros1, a potential growth suppressor on chromosome 1: its identity to basement membraneassociated proteoglycan, leprecan. Oncogene. 2000;19(32):3576-83.

27. Takagi H, Asano Y, Yamakawa N, Matsumoto I, Kimata K. Annexin 6 is a putative cell surface receptor for chondroitin sulfate chains. J Cell Sci. 2002; 115(Pt 16):3309-18.

28. Gattazzo F, Urciuolo A, Bonaldo P. Extracellular matrix: a dynamic microenvironment for stem cell niche. Biochim Biophys Acta. 2014;1840(8): 2506-19.

29. Wagers AJ. The stem cell niche in regenerative medicine. Cell Stem Cell. 2012:10(4):362-9.

30. Legate KR, Wickstrom SA, Fassler R. Genetic and cell biological analysis of integrin outside-in signaling. Genes Dev. 2009;23(4):397-418.

31. Brizzi MF, Tarone G, Defilippi P. Extracellular matrix, integrins, and growth factors as tailors of the stem cell niche. Cur Opin Cell Biol. 2012;24(5):645-51.

32. Roberts-Clark DJ, Smith AJ. Angiogenic growth factors in human dentine matrix. Arch Oral Biol. 2000;45(11):1013-6.

33. Nakashima M. Induction of dentine in amputated pulp of dogs by recombinant human bone morphogenetic proteins-2 and -4 with collagen matrix. Arch Oral Biol. 1994:39(12):1085-9.

34. Almushayt A, Narayanan K, Zaki AE, George A. Dentin matrix protein 1 induces cytodifferentiation of dental pulp stem cells into odontoblasts. Gene Ther. 2006;13(7):611-20.

35. Liu H, Li W, Gao C, Kumagai Y, Blacher RW, DenBesten PK. Dentonin, a fragment of MEPE, enhanced dental pulp stem cell proliferation. J Dent Res. 2004;83(6):496-9.

36. Kim SY, Kim MJ, Jung H, Kim WK, Kwon SO, Son MJ, et al. Comparative proteomic analysis of human somatic cells, induced pluripotent stem cells, and embryonic stem cells. Stem Cells Dev. 2012;21(8):1272-86.

37. Wang S, Tian R, Li L, Figeys D, Wang L. An enhanced chemically defined SILAC culture system for quantitative proteomics study of human embryonic stem cells. Proteomics. 2011;11(20):4040-6. 